\title{
Does size matter? The influence of shoe-hole sizes on foot-mounted marker motion during walking gait
}

\author{
Chris Bishop ${ }^{1 *}$, John B Arnold ${ }^{1}$, Francois Fraysse ${ }^{1}$, Dominic Thewlis ${ }^{1,2,3}$ \\ From 4th Congress of the International Foot and Ankle Biomechanics (i-FAB) Community \\ Busan, Korea. 8-11 April 2014
}

\section{Background}

To quantify in-shoe foot kinematics, studies have relied on cutting holes in the shoe upper to allow markers to be placed on the foot. Although previous research has suggested optimum hole sizes to preserve the structural integrity of the shoe [1], there is no empirical basis for what size holes are required to allow free-motion of individual markers during gait. The aim of this study was to determine the effect of different diameter holes on skinmounted marker motion during walking in athletic footwear.

\section{Methods}

Eighteen healthy adults participated in this study (10M:8F, mean age 22.7 years SD 3.7, height $1.74 \mathrm{~m} \mathrm{SD}$ 0.08 , body mass $71.2 \mathrm{~kg}$ SD 8.5). Wand-mounted surface markers were attached directly to the foot [2] or directly to the foot for barefoot measurements, which were used as a reference for comparisons. Each participant performed five walking trials in athletic footwear (ASICS Gel-Pulse 3). Three sets of identical shoes were used with holes of $15 \mathrm{~mm}(\mathrm{~A}), 20 \mathrm{~mm}$ (B) and $25 \mathrm{~mm}(\mathrm{C})$. All conditions were tested in a random order. Marker

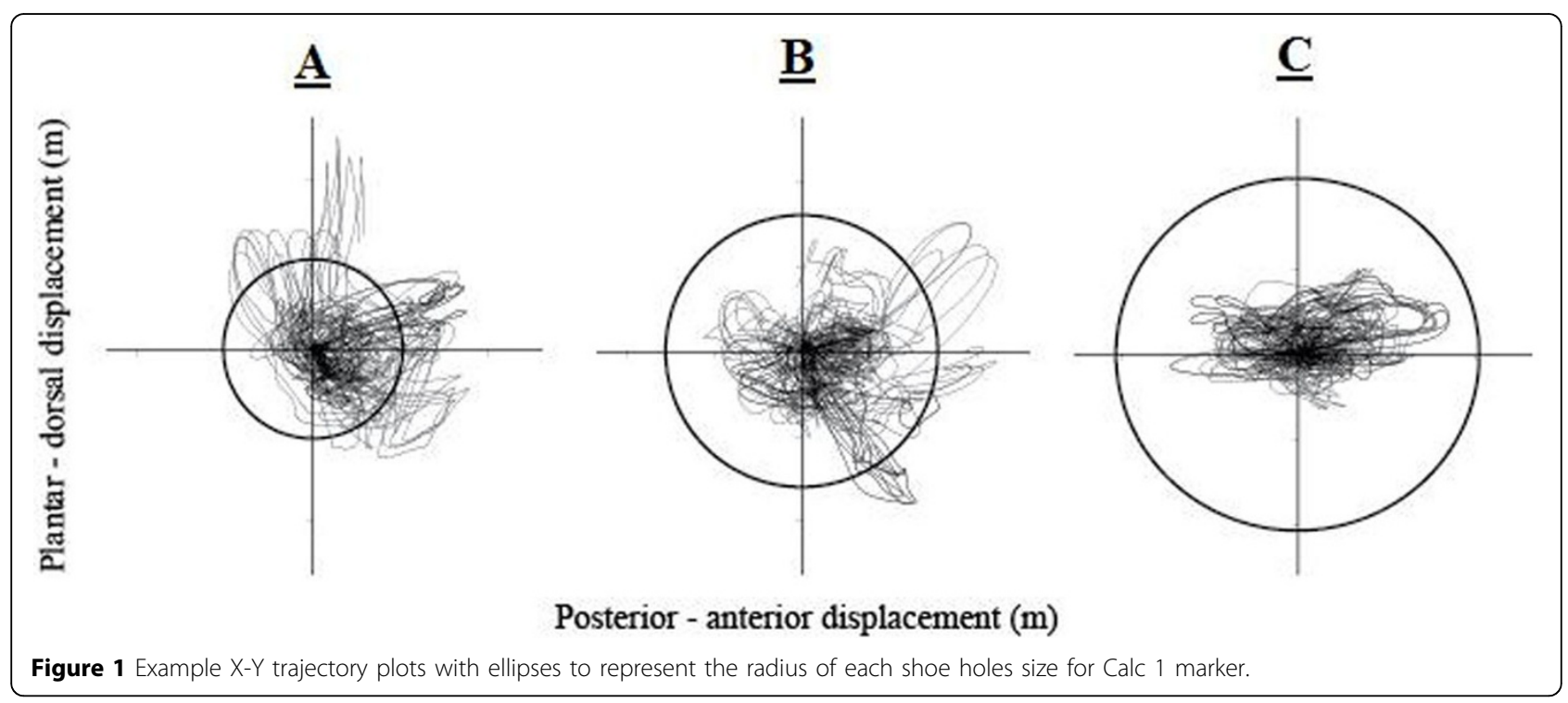

\footnotetext{
* Correspondence: Christopher.bishop@mymail.unisa.edu.au

'Biomechanics and Neuromotor Laboratory, School of Health Sciences,

University of South Australia, Australia

Full list of author information is available at the end of the article
} 
trajectories were acquired with 12 VICON cameras (MX-F20, VICON, UK) at $100 \mathrm{~Hz}$. Data analysis was conducted in two parts; firstly, the movement (marker trajectory) of individual markers relative to the origin of a fixed shoe reference frame was quantified. Secondly, we adapted a method proposed by Cappozzo et al. [3] quantified the isotropy of the marker motion on a plane.

\section{Results}

Where movement of the markers in the 15 and $20 \mathrm{~mm}$ conditions were restricted by the surrounding shoe upper, the marker movement in the $25 \mathrm{~mm}$ condition did not exceed the radius of any of the shoe-holes. Despite significant differences in the isotropy index between $25 \mathrm{~mm}$ and barefoot at the medial and lateral calcaneus markers $(P<0.05)$, the differences identified were due to the effect of footwear on the foot and not a result of the marker wands hitting the shoe upper.

\section{Conclusion}

When quantifying in-shoe foot kinematics, the size of the holes cut in the shoe upper can have a significant impact on the motion of surface markers attached to the foot. Using the methods in this study, it appears hole diameters smaller than $25 \mathrm{~mm}$ resulted in a restriction of surface marker motion, which may impact upon the resultant joint kinematics.

\section{Authors' details}

${ }^{1}$ Biomechanics and Neuromotor Laboratory, School of Health Sciences, University of South Australia, Australia. ${ }^{2}$ Sansom Institute for Health Research, University of South Australia, Australia. ${ }^{3}$ Centre for Orthopaedic and Trauma Research, University of Adelaide, Australia.

Published: 8 April 2014

\section{References}

1. Shultz $\mathrm{R}$, Jenkyn $\mathrm{T}$ : Determining the maximum diameter for holes in the shoe without compromising shoe integrity when using a multi-segment foot model. Med Eng Phys 2012, 34:118-122

2. Bishop C, Paul G, Thewlis D: The reliability, accuracy and minimal detectable difference of a multi-segment kinematic model of the footshoe complex. Gait Posture 2013, 37:552-557.

3. Cappozzo A, Cappello A, DellaCroce U, Pensalfini F: Surface-marker cluster design criteria for 3-D bone movement reconstruction. IEEE Trans Biomed Eng 1997, 44:1165-1174.

\section{doi:10.1186/1757-1146-7-S1-A7}

Cite this article as: Bishop et al:: Does size matter? The influence of shoe-hole sizes on foot-mounted marker motion during walking gait. Journal of Foot and Ankle Research 2014 7(Suppl 1):A7.

\section{Submit your next manuscript to BioMed Central} and take full advantage of:

- Convenient online submission

- Thorough peer review

- No space constraints or color figure charges

- Immediate publication on acceptance

- Inclusion in PubMed, CAS, Scopus and Google Scholar

- Research which is freely available for redistribution

Submit your manuscript at www.biomedcentral.com/submit 